\title{
ESPIRITUALIDADE NA EDUCAÇÃO POPULAR EM SAÚDE
}

\author{
EyMARD MOURÃO VASCONCELOS
}

RESUMO: A dimensão espiritual sempre esteve presente em grande parte das práticas de educação popular, mas de forma não claramente reconhecida nas análises teóricas. $\mathrm{O}$ instrumental teórico dos estudos sobre espiritualidade permite entender muitas dimensôes emocionadas e simbólicas que são marcas centrais da dinâmica educativa destas práticas. Este trabalho procura refletir o significado da espiritualidade como instrumento e espaço de relação educativa entre profissionais e usuários dos serviços de saúde, na luta pela saúde, foco usualmente não discutido nos estudos teóricos predominantes sobre o tema.

Palavras-chave: Espiritualidade. Educação popular. Educação popular em saúde. Espiritualidade na saúde.

\section{SPIRITUALITY WITHIN POPULAR EDUCATION IN HEALTH}

ABSTRACT: The spiritual dimension has always been present in most of the popular education practices, but without a clear recognized form of theoretical analysis. The theoretical instrument derived from studies of spirituality helps to better understand dimensions linked to emotions and symbols, which are central to the educative dynamic of those practices. This work tries to reflect on the signification of spirituality as an instrument and space of educative relationship in-between professionals and users of health services in their fights for health. Such a focus is usually not discussed in the predominant theoretical studies of this field.

Key words: Spirituality. Popular education. Popular education in health. Spirituality in health.

Doutor em Medicina e professor do Departamento de Promoção da Saúde da Universidade Federal da Paraíba (UFPB). E-mail: eymard.vasconcelos@gmail.com 


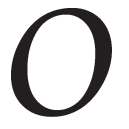

trabalho em saúde sempre esteve ligado às práticas religiosas. Mesmo com o advento da modernidade e o surgimento da medicina científica, estudos antropológicos atuais têm mostrado que a consideração de dimensões religiosas continua presente em todos os estratos sociais como parte importante da compreensão do processo de adoecimento e cura (Ibánez \& Masiglia, 2000). Mas a visão dualista inerente ao paradigma newtoniano e cartesiano de ciência, que separa o mundo da matéria do mundo do espírito, tornou ilegítima a consideração das dimensōes religiosas da vida humana na investigação da gênese das doenças e na busca de medidas terapêuticas. Por causa da suspeita do modelo newtoniano-cartesiano de ciência em relação à religião, profissionais, professores e pesquisadores do setor de saúde se envergonham de trazer, para o debate científico e para a discussão aberta nos espaços de formação dos recursos humanos em saúde, os saberes e vivências religiosas tão importantes em suas vidas privadas. Desta forma, as práticas religiosas têm estado presentes no trabalho de saúde de forma pouco crítica e elaborada, na medida em que nele se infiltram de modo silencioso e não debatido.

Contudo, a crescente manifestação de insatisfações ao modelo da biomedicina (Blendon, 1990), o fortalecimento da crítica aos pressupostos filosóficos da racionalidade científica, a partir da segunda metade do século XX, e o surpreendente aumento dos movimentos religiosos, no final do mesmo século, criaram condiçôes para o florescimento de uma extensa literatura, proclamando ideias e estratégias de saúde integradas a uma visão religiosa (Boff, 1999; Pietroni, 1988; Crema, 1995; Remem, 1998; Leloup, 2007; Amatuzzi, 2005; Koenig, 2005; Angerami-Camon, 2004; O Mundo da Saúde, 2007). Estas publicaçôes passam a ser consumidas amplamente, tanto pela população como pelos profissionais de saúde. Apesar desta mudança cultural, os estudos acadêmicos em saúde continuam extremamente fechados à incorporação de aspectos religiosos no entendimento do processo de adoecimento e cura. No Brasil, só recentemente uma revista científica de renome dedicou um número especial ao tema (Revista de Psiquiatria Clínica, 2007).

$\mathrm{O}$ avanço das ciências da religião, na medida em que possibilitou a criação de conceitos e análises desvinculados de uma tradição religiosa específica e, assim, de uma linguagem comum, está possibilitando a discussão mais ampla deste tema, de uma forma que supera parcialmente as usuais e tensas competições entre os vários grupos religiosos. 
O Brasil passou, na segunda metade do século xx, por um imenso processo de transição do perfil de distribuição das doenças, em que as patologias predominantes deixaram de ser as doenças infecciosas e parasitárias para serem as crônico-degenerativas (Barreto \& Carmo, 1995). O enfrentamento deste tipo de problemas de saúde não acontece com ações curativas pontuais, como é possível com a maioria das doenças infecciosas e parasitárias. Exige modificações profundas do modo de vida que só acontecem se é mobilizada uma grande "garra" nos pacientes e nos grupos, algo que a educação em saúde tradicional, centrada no repasse de informações, pouco acrescenta. Encontra-se aí a força da espiritualidade como instrumento de promoção da saúde, na medida em que lida com as dimensôes pouco conscientes do ser em que se assentam os valores, motivações profundas e sentidos últimos da existência individual e coletiva. Os portadores de doenças graves vivem crises subjetivas intensas e mergulham com profundidade em dimensões inconscientes da subjetividade. É nessa elaboração subjetiva profunda que são construídos novos sentidos e significados para suas vidas, capazes de mobilizá-los na difícil tarefa de reorganização do viver exigida para a conquista da saúde. Há uma milenar tradição do uso da espiritualidade no enfrentamento dos problemas de saúde que pode ser resgatada, mas que necessita ser atualizada para as atuais características da sociedade.

A crise existencial trazida pela doença leva o paciente e seu grupo social a importantes questionamentos sobre suas vidas. São questionamentos intensamente impregnados de emoção, em que elementos inconscientes da subjetividade participam intensamente. Podem resultar em amplas transformaçōes positivas ou em grandes catástrofes pessoais e familiares. A participação do profissional de saúde neste processo de elaboração é dificultada pelo fato de sua formação não valorizar e não prepará-lo para lidar com dimensôes subjetivas não expressas de forma racional e clara. Como lidar com estas dimensões?

Neste trabalho, parte-se da compreensão de que a educação popular contém instrumentos teóricos e práticas para a abordagem educativas destas dimensões. Procurando explicitar a presença da dimensão espiritual nas práticas de educação popular, usualmente não discutida nos estudos teóricos predominantes sobre o tema, busca mostrar a forma como ela pode contribuir para lidar com as dimensões espirituais presentes no trabalho em saúde. 


\section{A forma como a espiritualidade tem estado presente nas práticas de educação popular}

A educação em saúde é o campo de prática e conhecimento do setor saúde que se tem ocupado mais diretamente com a criação de vínculos entre a ação médica e o fazer cotidiano e o pensar da população. Diferentes concepções e práticas têm marcado a história da educação em saúde no Brasil. Mas, até a década de 1970, foi basicamente uma iniciativa das elites políticas e econômicas e, portanto, subordinada aos seus interesses. Voltava-se para a imposição de normas e comportamentos por elas considerados adequados, num tipo de educação que poderia ser chamada de "toca-boiada", em que os técnicos e a elite vão tentando conduzir a população para os caminhos que consideram corretos, usando, para isso, tanto o berrante (a palavra) como o ferrão (o medo e a ameaça). A participação de profissionais de saúde nas experiências de educação popular, a partir dos anos de 1970, trouxe para o setor da saúde uma cultura de relação com as classes populares que representou uma ruptura com a tradição autoritária e normatizadora da educação em saúde (Vasconcelos, 1997). Consolidou-se no setor de saúde um movimento organizado de profissionais entusiasmados com a potencialidade da educação popular, como instrumento de construção de uma atenção à saúde mais integral, a Rede de Educação Popular e Saúde, que vem procurando desenvolver e divulgar um saber necessário para um trabalho articulado entre os serviços de saúde e as iniciativas dos sujeitos e movimentos das classes populares.

No campo da saúde, a educação popular tem sido utilizada como uma estratégia de superação do grande fosso cultural existente entre os serviços de saúde e o saber dito científico, de um lado e, de outro lado, a dinâmica de adoecimento e cura do mundo popular. Atuando a partir de problemas de saúde específicos ou de questōes ligadas ao funcionamento global dos serviços, busca entender, sistematizar e difundir a lógica, o conhecimento e os princípios que regem a subjetividade dos vários atores envolvidos, de forma a superar as incompreensões e mal-entendidos ou tornar conscientes e explícitos os conflitos de interesse. A partir deste diálogo, soluções vão sendo delineadas. Neste sentido, a educação popular tem significado não uma atividade a mais que se realiza nos serviços de saúde, mas uma ação que reorienta a globalidade das práticas ali executadas, contribuindo na superação do 
biologicismo, autoritarismo do doutor, desprezo pelas iniciativas do doente e seus familiares e da imposição de soluçôes técnicas restritas para problemas sociais globais, que dominam na medicina atual. É, assim, um instrumento de construção de uma ação de saúde mais integral e mais adequada à vida da população.

Educação popular é o saber que orienta nos difíceis caminhos, cheios de armadilhas, da ação pedagógica voltada para a apuração do sentir/pensar/agir dos setores subalternos para a construção de uma sociedade fundada na solidariedade, justiça e participação de todos.

Ela, desde a sua origem nos meados do século xx, esteve muito ligada ao campo religioso, seja pela origem cristã de muitos de seus pioneiros, seja pela estreita ligação de suas práticas com as pastorais, principalmente da Igreja Católica, após o golpe militar de 1964. A partir dos anos de 1970, as igrejas cristãs, que conseguiram resistir à repressão política da ditadura, se tornaram espaços privilegiados de apoio às iniciativas de educação popular e, consequentemente, de delineamento de suas características. No mais famoso livro de Paulo Freire, Pedagogia do oprimido, escrito em 1968, as marcas desta espiritualidade já aparecem, em muitos momentos, em afirmaçôes como: "a fé no homem é o pressuposto do diálogo" ou "sendo fundamento do diálogo, o amor é, também, diálogo" (Freire, 1979, p. 95). Em escritos e depoimentos posteriores, ele assume com muito mais veemência a importância da religiosidade em seu pensamento. No entanto, a produção acadêmica sobre educação popular, refletindo o dualismo da ciência que divide o mundo em dois (o empírico e o espiritual ou, no dizer de Descartes, a natureza, de um lado, e a graça em teologia do outro [Durozoi \& Roussel, 1996, p. 141]), tendeu a ver a associação com o religioso como circunstancial. A religiosidade presente na maioria das práticas de educação popular seria apenas a linguagem de expressão possível, naquela cultura e naquele contexto político repressivo. A religiosidade presente em autores, como Paulo Freire, também foi percebida como peculiaridade de suas personalidades não aplicáveis à estrutura do pensamento e prática pedagógica da educação popular.

Não se quer, com isso, afirmar o caráter religioso da educação popular, mas sim que a forte presença da dimensão religiosa em suas práticas e na formulação de alguns dos pioneiros de sua sistematização teórica indica uma característica epistemológica de suas práticas que 
grande parte da reflexão sociológica e pedagógica não conseguiu captar. Se entendemos a religiosidade como a forma mais utilizada pela população para expressar e elaborar a integração das dimensões racional, emocional, sensitiva e intuitiva ou a articulação das dimensões conscientes e inconscientes de sua subjetividade e de seu imaginário coletivo (Valla, 2001), esta sua forte presença significa um avanço em seu método de perceber e tratar as interaçôes entre educador e educando, em relação ao pensamento sociológico e pedagógico, ainda preso ao paradigma modernista que continua dominante. Significa que a centralidade do diálogo no método da educação popular não se referia, nas suas práticas pedagógicas, apenas à dimensão do conhecimento e dos afetos e sensações conscientes, mas também às dimensões simbólicas do inconsciente, presentes nas relaçôes sociais. Nas práticas de educação popular conduzidas numa linguagem religiosa, dimensões inconscientes participam explicitamente de forma central dos diálogos que se estabelecem, através das metáforas das histórias míticas e dos símbolos da liturgia. Assim, o questionamento maior do saber popular, tão valorizado nas práticas de educação popular, ao pensamento moderno não está nos conhecimentos inusitados e surpreendentes que ele expressa sobre as estratégias da população adaptar-se à realidade onde vive, mas na sua forma de estruturar o conhecimento de uma forma que integra dimensões racionais, intuitivas e emocionais. Seu maior ensinamento para os profissionais de formação científica, que com ele interagem, é epistêmico, ou seja, questiona o paradigma ou o modelo geral como o pensamento tem sido processado na produção e estruturação do conhecimento considerado válido pela sociedade moderna. O saber popular não está submetido à ditadura do saber aprendido conscientemente e logicamente estruturado. Inclui e se articula com o saber que brota do corpo e que utiliza estados de inebriamento e excitação para se estruturar. Isso não foi captado pela maior parte da reflexão teórica sobre educação popular que se construiu.

A convivência intensa de alguns profissionais de saúde com as classes populares e os seus movimentos tem-lhes ensinado um jeito diferente de conduzir seus atos terapêuticos. Aprendem a romper com atitude fria dominante no modelo da biomedicina e passam a criar um vínculo emocional com as pessoas cuidadas, que gera um estado de alma aberto para ser afetado profundamente por elas. Este envolvimento com as pessoas cuidadas desencadeia intuições que são 
acolhidas e colocadas em operação no trabalho em saúde. Vai-se, com o tempo, adquirindo uma confiança neste agir orientado também pela emoção e a intuição. Aprende-se a valorizar percepções sutis dos sentidos. Vai-se também aprendendo a manejar, de forma equilibrada, a relação entre a razão, a emoção e a intuição na estruturação do ato terapêutico. A intuição traz à tona saberes produzidos nas estruturas arquetípicas do processamento mental inconsciente que foram descobertas por Jung, permitindo acessar saberes acumulados durante todo o processo histórico de construção da espécie humana, que são herdados por todos pela genética e pela assimilação de elementos simbólicos da cultura (Maroni, 1998).

Justamente por este aprendizado junto às classes populares propiciado pela convivência, têm sido os profissionais e pesquisadores do movimento da Educação Popular em Saúde que vêm tomando a frente para trazer o debate sobre o tema da espiritualidade no trabalho em saúde para o campo da saúde coletiva no Brasil.

Contudo, por que a mentalidade religiosa tem se mostrado tão presente na cultura das classes populares latino-americanas? O sociólogo chileno Cristian Parker afirma que o processo de modernização industrial, comandado pela lógica da ciência e da racionalidade técnica nos Estados Unidos e na Europa ocidental (e também em bolsões de prosperidade da América Latina), resultou no que se pode chamar de um conforto mínimo para a maioria da população destas regiōes do mundo (Valla, 2001). O relativo sucesso deste processo de modernização gerou o fenômeno da secularização, afastando o imaginário social da forma religiosa de organizar a subjetividade. Nestes locais, o discurso da modernidade foi incorporado fortemente até mesmo entre as classes populares. Já o processo de modernização na América Latina não teve um efeito claramente positivo para a maioria da população. Pelo contrário, aumentou enormemente a desigualdade e a percepção de subalternidade. Por esta razão, o processo de substituição da mentalidade religiosa por uma visão centrada na razão e na lógica científica foi muito menor. Apesar das intensas mudanças econômicas e sociais em países como o Brasil, a população continua com uma visão religiosa muito profunda. Para ele e outros pesquisadores, a religião popular é uma das características mais importantes da cultura das classes populares latino-americanas. Ela é a forma particular e espontânea de expressar os caminhos que estas classes escolhem para enfrentar suas dificuldades 
no cotidiano. A religião popular é um saber e uma linguagem de elaboração e expressão da dinâmica subjetiva, parte da cultura popular, em que a população se baseia para buscar o sentido de sua vida. Cria uma identidade mais coesa entre os grupos sociais, ajuda a enfrentar as ameaças e a ganhar novas energias para encarar a luta pela sobrevivência e pela alegria. É uma forma de resistência cultural ao modo de vida que a elite lhes quer impor. Assim, a questão religiosa das classes populares não pode ser vista como uma questão tradicional e arcaica. $\mathrm{O}$ importante não seria constatar a importância da religião para estas classes, mas a sua dinâmica de transformação que a faz uma resposta atualizada e renovada às intensas transformações sociais que estão acontecendo. É um instrumento de resistência à lógica da modernidade que ampliou a desigualdade e a injustiça. Uma estratégia de sobrevivência, em que a busca do sobrenatural tem a ver com a solução de problemas imediatos e cruciais e não com o investimento na vida após a morte.

Muitas das resistências dos intelectuais progressistas em valorizar a dimensão religiosa da população se devem à percepção de se tratar de um campo marcado pela dominação de uma hierarquia religiosa que tem se mostrado historicamente bastante autoritária e dogmática, bem como vinculada frequentemente ao poder político e econômico. Mas a importância da religiosidade na vida da população parece se dar não por uma identificação com estas hierarquias religiosas, mas pelo papel que ela assume na sua vida cotidiana. E há grandes diferenças entre a religiosidade popular e aquela difundida oficialmente. A religiosidade popular, como toda prática humana, é povoada de contradições e ambiguidades, de conformismo e resistência. A superação de suas dimensões negativas é um desafio a uma educação popular que a problematize. Mas, para isto, é preciso que se entenda a complexidade simbólica de suas práticas.

Nesse sentido, a ênfase no conceito de espiritualidade, ao invés de religiosidade, pode ajudar a desbloquear resistências, uma vez que se refere a práticas não necessariamente ligadas às religiōes. É um conceito que ressalta principalmente a dinâmica de aproximação com o eu profundo, que não corresponde necessariamente aos caminhos padronizados difundidos pelas hierarquias religiosas tradicionais. Mesmo líderes religiosos, como Boff (1999), afirmam que o decisivo não são as religiōes, mas a espiritualidade subjacente a elas. Assim, a priorização do conceito de espiritualidade tem um papel inclusivo em 
uma sociedade que tende para a diversidade cultural. E salienta a dimensão de vivência em detrimento da dimensão formal de ligação ou não com as instituições religiosas que, até a pouco, era mais valorizada.

Desde 1974, estou envolvido com o movimento da Educação Popular no Brasil. Algumas destas reflexões começaram a ser feitas por mim, a partir de uma conversa, em 1981, com o padre Celestino Grilo, que trabalhava comigo na pastoral dos direitos humanos, no interior da Paraíba. Ele afirmava que muitos intelectuais colaboradores das iniciativas educacionais da Diocese de Guarabira desvalorizavam a religiosidade presente nos grupos. Aceitavam-na apenas como estratégia de inserção no meio popular, pois a Igreja era ali a única instituição que dava suporte ao trabalho educativo junto às classes populares daquela região rural. Recorriam à linguagem religiosa de forma utilitarista apenas para terem acesso à população e serem ouvidos. Sonhavam com o dia em que poderiam assumir a problematização das questôes sociais de forma direta, objetiva e racional, sem ter que recorrer aos "volteios" da religiosidade. Ele notava, no entanto, que quando estes intelectuais organizavam iniciativas educativas, discutindo os problemas da população sem deixar espaço para ritos, comemorações, orações e dinâmicas reflexivas feitas de forma afetiva, os trabalhos não prosperavam.

\section{Tomada da inconsciência}

Na luta pela cidadania, é usual utilizar a expressão tomada de consciência, referindo-se à apropriação da capacidade da consciência de conhecer os direitos e deveres que todos devem ter, principalmente por parte daqueles que não têm acesso a estes direitos. Esta conscientização sobre os direitos e os caminhos de luta para conquistá-los no jogo político é, de fato, fundamental. Rolnik (1994), todavia, chama a atenção para sua insuficiência a partir de observação da realidade dos países mais avançados da Europa, onde há um sólido reconhecimento social dos direitos de cada cidadão que se traduz num grande respeito ao outro e, ao mesmo tempo, um distanciamento entre as pessoas, no que ela denominou de uma anestesia à interação afetiva, que se expressa por um cotidiano de solidão, apatia e sensação difusa de rejeição social. Há, então, um máximo reconhecimento do outro em sua condição de cidadania e um mínimo acolhimento do outro em sua totalidade. $\mathrm{Na}$ medida em que o inconsciente é o 
modo de apreensão e elaboração das dimensões invisíveis e misteriosas do ser humano integral, na construção de uma sociedade solidária, justa e saudável, seria então também importante a tomada da inconsciência, no sentido do cultivo, na sociedade, da capacidade de acolhimento afetivo e espiritual ao outro pelo aprendizado subjetivo da habilidade de lidar com as transformações e perturbações interiores que este encontro com a subjetividade, de quem é diferente, desencadeia, em uma sociedade de massa em que as pessoas estão continuamente se cruzando.

A valorização da tomada da inconsciência, integrada à tomada de consciência, aponta para um imaginário ético que vai além da luta pelo respeito aos direitos formais de todos. Orienta-se por uma ética que inclui também uma situação social de amplo acolhimento de cada cidadão em sua inteireza e, portanto, de extrema abertura ao processo de recriação subjetiva e de novos modos de existência. Uma sociedade que, além da justiça e direitos sociais reconhecidos, seja marcada pela intensa interação amorosa. Onde a abertura e entrega à processualidade da vida e às suas criativas e surpreendentes consequências sejam o valor maior.

O acréscimo da valorização da tomada da inconsciência à já bastante ressaltada tomada de consciência significa a incorporação do aprendizado de que, mais que respeitar o outro, é importante abrir-se ao outro, dispondo-se a viver a experiência de desapego aos arranjos subjetivos estabelecidos e consolidados em cada um, aceitando a impermanência da vida de forma mais radical.

Assim, pode-se dizer que uma educação popular restrita aos aspectos conscientes do problema humano é insuficiente, porque não aborda as dimensões intuitiva, sensorial e emocional de forma integrada à razão. Na América Latina, as relações sociais no meio das classes populares não são marcadas por este distanciamento afetivo, pois elas não estão tão subjugadas ao modo racionalista e utilitarista de manejo da subjetividade trazido pela modernidade. $\mathrm{O}$ processo de tomada da inconsciência está muito mais precário entre os intelectuais e técnicos educadores que, com seu poder, têm grande capacidade de moldar as relações educativas de que participam. As suas práticas pedagógicas, que impõem abordagens restritas aos aspectos conscientes do problema humano, acabam tolhendo a entrada na cena educativa desta vivacidade 
intuitiva presente no popular. Acabam esvaziadas, como notava o padre Celestino Grilo, já em 1981.

Recebido em abril de 2008 e aprovado em maio de 2009.

\section{Referências}

AMATUZZI, M.M. Psicologia e espiritualidade. São Paulo: Paulus, 2005. 239p.

ANGERAMI-CAMON, V.A. (Org.). Espiritualidade e prática clínica. São Paulo: Pioneira; Thomson, 2004. 263p.

BARRETO, M.; CARMO, E. Mudanças em padrões de morbimortalidade: conceitos e métodos. In: Monteiro, C. (Org.). Velhos e novos males da saúde no Brasil. São Paulo: HUCITEC, 1995.

BIOÉTICA, saúde e espiritualidade. O Mundo da Saúde, São Paulo, v. 31, n. 2, abr./jun. 2007.

BLENDON, R. et al. Satisfaction with health systems in ten nations. Health Affairs, Bethesda (USA), v. 9, n. 2, p. 185-192, 1990.

BOFF, L. Saber cuidar: ética do humano - compaixão pela terra. Petrópolis: Vozes, 1999.

CREMA, R. Saúde e plenitude: um caminho para o ser. 3. ed. São Paulo: Summus, 1995.

DUROZOI, G.; ROUSSEL, A. Dicionário de filosofia. 2. ed. Campinas: Papirus, 1996.

ESPIRITUALIDADE e saúde mental. Revista de Psiquiatria Clinica, São Paulo, v. 34, supl. 1, 2007.

FREIRE, P. Pedagogia do oprimido. 6. ed. Rio de Janeiro: Paz \& Terra, 1979.

IBÁNEZ, N.; MARSIGLIA, R. Medicina e saúde: um enfoque histórico. In: CANesqui, A.M. (Org.). Ciências sociais e saúde para o ensino médico. São Paulo: HUCITEC, 2000. p. 49-74. 
KOENIG, H.G. Espiritualidade no cuidado com o paciente: por que, como, quando e o quê. São Paulo: Fé Editora Jornalística, 2005.

LELOUP, J.-Y. Uma arte de cuidar: estilo alexandrino. Petrópolis: Vozes, 2007.

MARONI, A. Jung, individuação e coletividade. São Paulo: Moderna, 1998.

PIETRONI, P. Viver holístico. 2. ed. São Paulo: Summus, 1988.

REMEN, R.N. Histórias que curam: conversas sábias ao pé do fogão. São Paulo: Ágora, 1998.

ROLNIK, S. Cidadania e alteridade: o psicólogo, o homem da ética e a reinvenção da democracia. In: SpInK, M.J.P. (Org.). A cidadania em construção: uma reflexão transdisciplinar. São Paulo: Cortez, 1994. p. 157-176.

VALLA, V.V. O que a saúde tem a ver com a religião. In: VALLA, V.V. (Org.). Religião e cultura popular. Rio de Janeiro: DP\&A, 2001. p. 113139.

VASCONCELOS, E. Educação popular nos serviços de saúde. 3. ed. São Paulo: HUCITEC, 1997. 